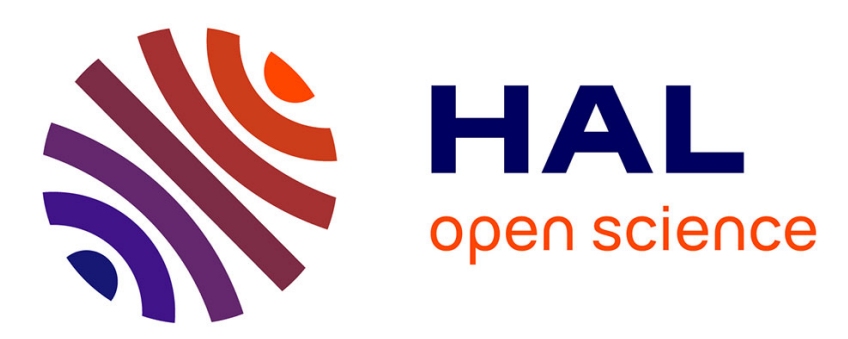

\title{
Virtual tyre production: Learning industrial process through an Informed Virtual Environment
}

\author{
Jérôme Olive, I.M. Thouvenin
}

\section{To cite this version:}

Jérôme Olive, I.M. Thouvenin. Virtual tyre production: Learning industrial process through an Informed Virtual Environment. Multimedia and Expo (ICME), 2011 IEEE International Conference on, Jul 2011, Barcelona, Spain. pp.1 -4, 10.1109/ICME.2011.6012068 . hal-00979500

\section{HAL Id: hal-00979500 https://hal.science/hal-00979500}

Submitted on 16 Apr 2014

HAL is a multi-disciplinary open access archive for the deposit and dissemination of scientific research documents, whether they are published or not. The documents may come from teaching and research institutions in France or abroad, or from public or private research centers.
L'archive ouverte pluridisciplinaire HAL, est destinée au dépôt et à la diffusion de documents scientifiques de niveau recherche, publiés ou non, émanant des établissements d'enseignement et de recherche français ou étrangers, des laboratoires publics ou privés. 


\title{
VIRTUAL TYRE PRODUCTION: LEARNING INDUSTRIAL PROCESS THROUGH AN INFORMED VIRTUAL ENVIRONMENT
}

\author{
Jérôme Olive - Indira Mouttapa Thouvenin \\ jerome.olive@hds.utc.fr - indira.thouvenin@hds.utc.fr \\ Heudiasyc Laboratory - University of Technology of Compiègne - France
}

\begin{abstract}
This paper presents an industrial application called "RVPI" [1] for training operators in a tyre manufacturing plant. This training is performed through an Informed Virtual Environment integrating different aspects of human activity and expertise. To create the system, knowledge extraction and a codesign of the system have been realized in collaboration with the German tyre manufacturer Continental. The system is deployed in real plants in five different countries and is now becoming a regular training tool. Results show that production costs are reduced with RVPI due to a shorter training period and a better understanding of the process.
\end{abstract}

Index Terms - Industrial training, informed virtual environnement, tyre production, virtual reality

\section{INTRODUCTION}

For several years virtual environments in many studies were focused on modelling and simulating realistic systems. However, less attention has been paid toward the integration of human activity knowledge in the virtual environment where interaction is needed. When examining training for manufacturing several parameters are emerging:

- the increasing level of technological tools (computerized machines, industrial automatons )

- the lack of qualified operators

- the need to reduce the training period

The impact of training on production is very heavy: reducing the training duration and improving the quality means reducing the production cost. A virtual reality system can answer these requirements and offers the possibility to replace a real machine by a virtual one during the training, which brings a better productivity. The German tyre manufacturer, Continental was interested to reduce the training period from eight to six weeks and to increase the level of knowledge of new operators with a virtual reality based training system.

\subsection{Tyre manufacturing and Informed Virtual Environ- ments (EVI) for training}

To enforce safety functions and comfort while resisting to damage (UV, wear, heat, etc.) a tyre is composed of no less than fifteen different rubbers, each one destined to a specific location: side wall, tread, inner liner, bead apex, etc. Among the 75 to 80 products used for tyre manufacturing we can distinguish the natural rubber (12\%), the synthetic rubber, silica, carbon powder, oils (specially turnip oil which has a plasticizing capacity and a resistance to low temperatures), sulphur for vulcanization, activators and accelerators to allow better homogeneity of the mix. A semi-automatic machine assembles the external part of the tyre before vulcanization, which means the carcass constituted of the tread and its internal part serving as a tube.

Manufacturing with virtual reality [2] may be divided into three fields of industrial activity:

- the first one is the planning which makes it possible to envisage flows of production and to organize the various production stages

- the second one is the simulation as a mean of displaying the results and sharing visualisation

- the last one is the training where virtual reality allows learning of tasks on a virtual machine without danger, stress and production interruption.

Several training systems have been developed with this in mind. A welding simulator developed for the AFPA (French association for technical learning) named CS-Wave [3] trains the user the technical gesture and improves their understanding of the invisible phenomena in the real world. Arvi [4] allows fire fighters to be immersed in a fire or a catastrophe crisis through a virtual environment. Fiacre [5] is a system where high speed train drivers are trained on railway interventions. Tyre manufacturing with virtual reality (VR) is a new application to train operators on a complex and very expensive machine. Our system is called RVPI (Ralit Virtuelle pour la Production Industrielle) is a new training system based on virtual reality system. This VR system is composed of two 


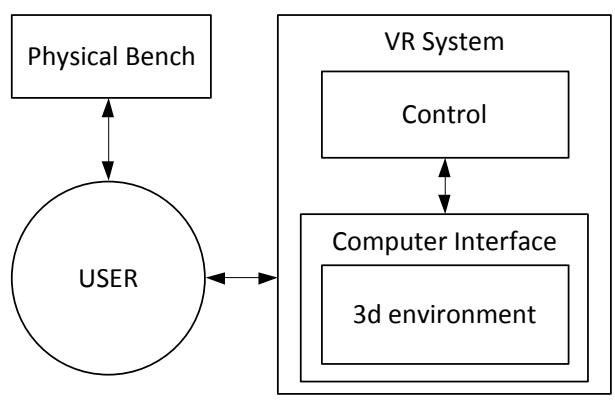

Fig. 1. VR manufacturing tool.

interfaces and a physical bench (Figure 1). The first interface is 3D , representing the operator's station (production machine and its environment), in which the operator's aim is to produce a part of the tyre. The second interface is a real machine's control panel connected to the VR environment; it allows the user to control the manufacturing machine in the real world and its digital representation in the VR system. We suppose that our system is useful for the comprehension of the machine functions, but not on the material manipulation gesture training. We have therefore added to the VR system an old machine named the "physical bench" in order to train the operator on specific manual tasks. On the virtual machine we can visualize the complete tyre building process. This process can be carried out in a correct way or a degraded way. In the second case, we can modify several parameters of the machine to simulate a malfunction, thus allowing the operator to learn how to correct them. Interaction and navigation are free in virtual visit and test modules and limited for predefined procedures to learn.

We do not represented a physicaly realistic process in the 3D scene; our goal is to understand the tyre building process and the adjustments made on the machine instead of simulating the physical assembly of tyres, like rubber bending and welding. In a lot of cases, knowledge is either completely dissociated from the environment (for example 2D texts displayed above the 3D scene) or associated to the environment and become full objects of the environment. We propose knowledge based models accessible in the 3D scene, and we explore the possibilities of virtual reality interfaces to add perceptive knowledge to the environments as in [6].

\section{BUILDING RVPI}

\subsection{Knowledge extraction}

The first knowledge extraction was related to the pedagogical aspects of the training. A pedagogical method was used to define the training manuals after some interviews with various actors (operators, training manager, production technicians, quality technicians and trainers). Safety and quality rules were represented in the manuals and in the system. Manuals are the link between the virtual environment and the physical bench. The second knowledge extraction was focused on technical aspects of the machine and was based on discussions between Continental and us. This extraction is included in a collaborative design phase.

\subsection{Collaborative design method}

For the design of this system (Figure 2) we adopted the following method. Actors in connection with the project such as engineers and VR experts worked with Continental operators and trainers. The first step was an ergonomic tasks study, performed by an independent entity. After this study, the actors identified precisely the real manufacturing process on the machine to be simulated and a first 3D virtual machine was modelled. Then the manufacturing process was divided into elementary actions (example: go to that part of the machine, start this command ...). These actions were scheduled according to the procedure of the real machine, resulting into the VTMP (virtual tyre manufacturing process) of all operations of the machine. The VTMP is a scheduled description of all the simulation elementary parts. The virtual machine and the VTMP were evaluated according to the criteria of industrial safety and quality (respect of security area, security equipment used by the avatar, presence of Kanban cards) In figure 2 , we see the complete collaborative design-process.

\subsection{System architecture}

The digital parts of RVPI (Figure 3) consists of two different interfaces. The first one is an industrial control panel including the real machine controller. The second element is the digital environment. This environment is made of a database and an html interface with a 3D module (Virtools [7]) for interactive representation of the virtual machine (Figure 4). A training tracking module provides training sessions data collection. International deployment is enabled by a multilingual web interface. We synchronize the 3D mock-up with the PLC (Programmable Logic Controller) through an OPC connection. The OPC is a standard protocol for communication with PLCs. This communication is ensured through a Virtools plugin, developed internally.

\section{RESULTS AND DISCUSSION}

\subsection{Results}

Our system was designed as a central tool in a new industrial training. The main goal of this new training system was to reduce the training period from eight to six weeks and to increase the level of knowledge of new operators. Actually most parts of the training period were done in four or five weeks which is a good first result. Another advantage is the 


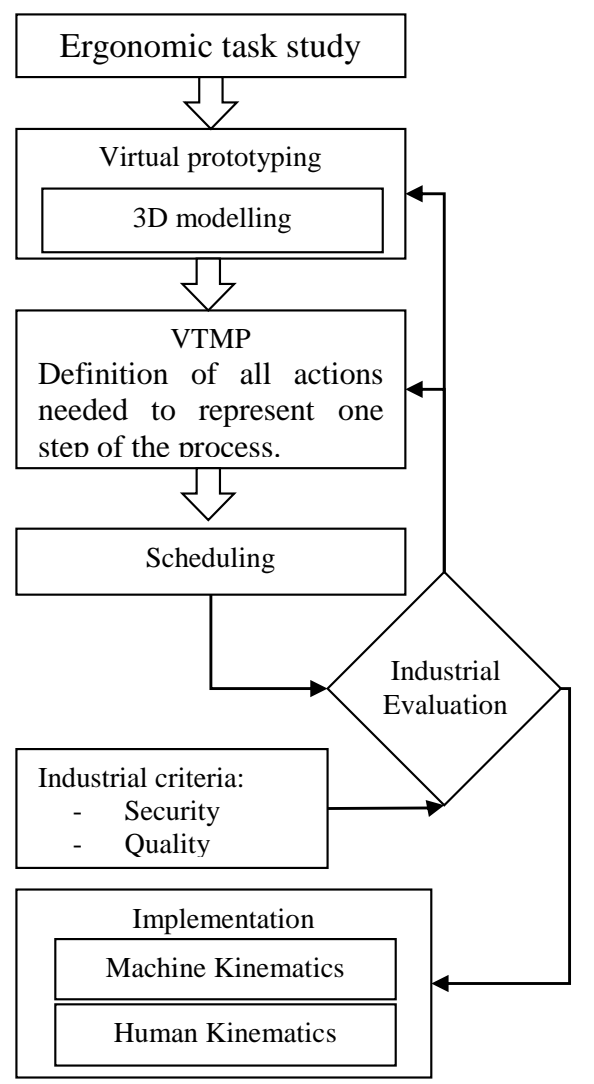

Fig. 2. Collaborative design method

increased production because the RVPI system provides a virtual machine and frees the real one which becomes available for the other operators.

In the RVPI training, the machine running-time (Figure 5) represents only $50 \%$ of the training time. Three weeks against eight represent a $60 \%$ gain. In reality, we can even reduce it to 2.5 or 2 weeks depending on the trainee, so almost a $75 \%$ gain. It is due to the use of the system in the first weeks.

Figure 6 shows the comparison between the operators' efficiency during the previous and new training with the system. The new training efficiency values was recorded on 14 new trained operators and previous training efficiency values was provided by the process enginnering department. Efficiency is the number of good tyres (without defects) produced by an operator per the standard number of tyres defined by the process engineering department of the plant. Comparatively, in the new training, operators have a capacity to produce the early days much higher during the training. This means that when moving to production, trainees have production rates equivalent to $50 \%$ of standard production. This improvement saves the otherwise lost production from the first day of training. Although the increase in efficiency is lower compared to the previous training, the level of efficiency is much higher in this new training right from the first day. One can eas-

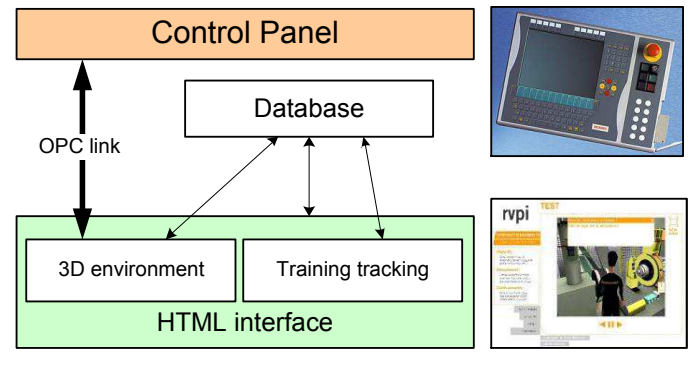

Fig. 3. RVPI system architecture.

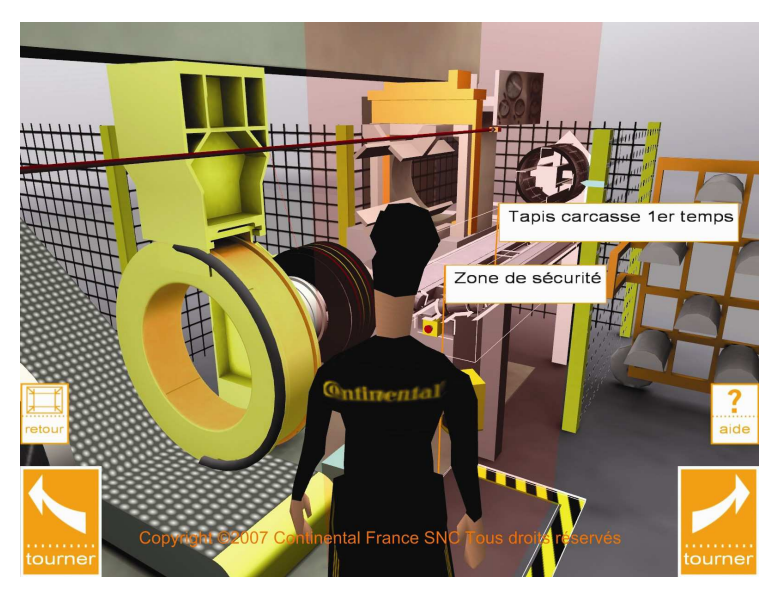

Fig. 4. RVPI 3D environment.

ily deduce, that the operators are quicker able to use the machine with the new training. Moreover, these results don't use other parameters such as level of knowledge that cannot be compared to the previous training, because the new training involves much broader knowledge than the previous one, including the settings and malfunctions.

The gain in production through the new formation was estimated to 2200 tyres produced, about 4 men by day of production over the 6 weeks of training. In addition, during the time earned on the training, operators can produce more tyres from the start of training. The same training system was installed in Romanian plant and it was evaluated. Results show that Romania operators are 54\% more efficient when they used the system during the training and the quality level increases by $25 \%$ from the previous training directly on machine. As in the French plant, the training time is reduced by $50 \%$ and the machine is freed during system training.

\subsection{Discussion}

It is indisputable that these results are industrial performance and not results recorded in controlled experimental conditions. However, they reveal that learning in a virtual environment is suitable for understanding complex processes and 


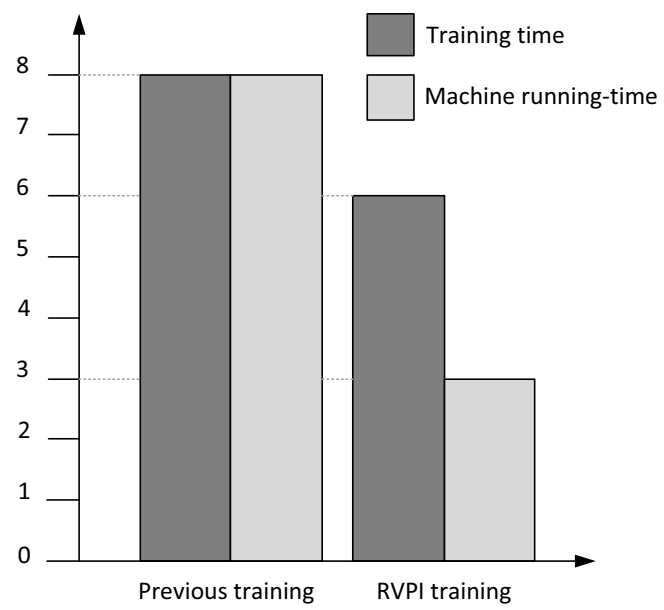

Fig. 5. Training duration comparison.

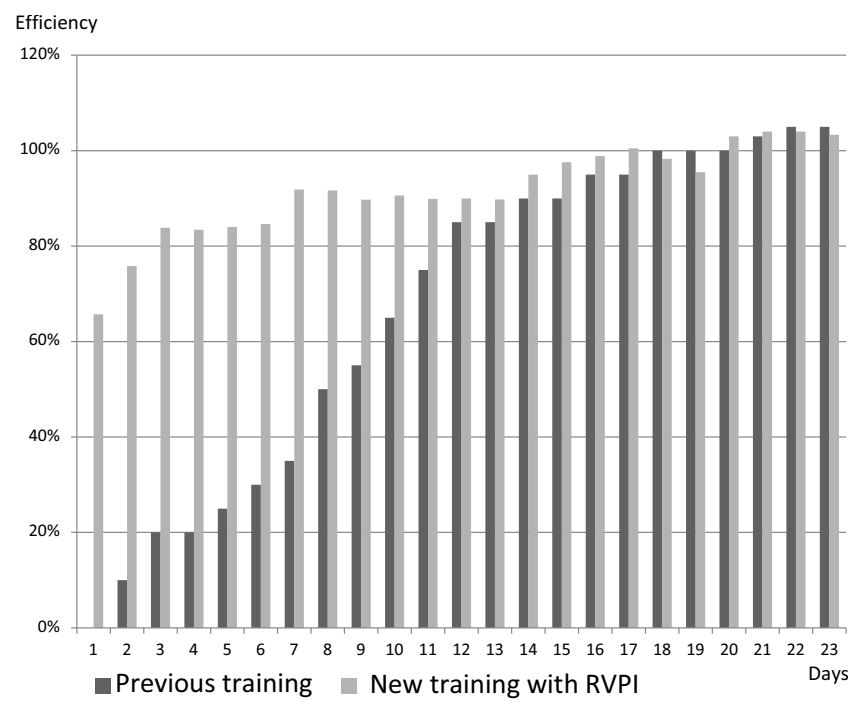

Fig. 6. Operators efficency day by day during the training.

that even in comparison with the training on the real system. To explain these results we can highlight the use of virtual reality to reduce the anxiety of the learner. Indeed, the user is less distracted by fear of doing wrong actions and being faced with a stressful and impressive machine, he can concentrate on understanding the manufacturing process. In addition, the use of virtual reality allows a decomposition of this process specific training

\section{CONCLUSION AND PERSPECTIVES}

The RVPI training system provides a case study in the use of Virtual Reality in a real manufacturing plant. Five countries are now using it daily, and the project won a prize (Imagina 2008) in the category "Industry/best performance". The dif- ficulty in this work was to select the process scenario among a lot of possibilities, including malfunctions. A knowledge extraction based on the pedagogical expertise of our team and a co -designing method between the plant employees and the university has led us to a system composed of two parts:

- a real digital control panel

- an informed virtual environment

Industrial results show a decrease in the training period and a better performance for tyre production. Another VR tool has emerged from the RVPI project with the creation of a startup Reviatech[8] (France). We explore the possibility to extend the principles of informed virtual environment to a maintenance case, taking into account gesture of expert.

\section{REFERENCES}

[1] "Rvpi," http://www.hds.utc.fr/RVPI/, checked in april 2011.

[2] T. S. Mujber, T. Szecsi, and M. S. J. Hashmi, "Virtual reality applications in manufacturing process simulation," Journal of Materials Processing Technology, vol. 155156, pp. $1834-1838,2004$, Proceedings of the International Conference on Advances in Materials and Processing Technologies: Part 2.

[3] Laurent Da Dalto, "Welding training in a virtual environment," Tech. Rep., Communication System France, 2004.

[4] R. Querrec, C. Buche, E. Maffre, and P. Chevaillier, "Multiagents systems for virtual environmentfor training application to fire-fighting," in IASTED InternationalConference on Computers and AdvancedTechnology in Education, 2003, pp. 647-652.

[5] W. Bouslimi, M. Kassaagi, D. Lourdeaux, and Ph. Fuchs, "Modelling driver behavior in a straight-line emergency situation," Transactions Journal of Passenger Cars: Electronic and Electrical Systems, vol. 1, no. 1, pp. 743751, march 2005.

[6] L. Fricoteaux, I. MouttapaThouvenin, and T. Voillequin, "Quiver: an informed virtual environment for thermal data perception for housing," in Joint Virtual Reality Conference (EGVE - ICAT - EuroVR), Lyon, France, 2009.

[7] "Virtools," http://www.3dvia.com/products/3dviavirtools/, checked in april 2011.

[8] "Reviatech," http://www.reviatech.com/, checked in april 2011. 